\title{
Early-stage concentrations of formaldehydes and TVOCs in a new low-energy building
}

\author{
Angela Sasic Kalagasidis ${ }^{1,}$, Fredrik Domhagen ${ }^{1}$, and Sarka Langer $^{2}$ \\ ${ }^{1}$ Department of Architecture and Civil Engineering, Chalmers University of Technology, S-41296 Gothenburg, Sweden \\ ${ }^{2}$ IVL Swedish Environmental Research Institute, P.O. Box 53021, SE-40014 Gothenburg, Sweden
}

\begin{abstract}
This paper deals with temporary discomfort caused by characteristic odours from new objects and materials in office buildings. Earlier investigations have shown that increased ventilation rates in residential buildings decrease the indoor concentrations of non-occupant-related indoor air pollutants such as aldehydes and total volatile organic compounds (TVOCs). To study how this basic principle for the control of indoor air pollutants complies with a demand-controlled ventilation, which is an important energy efficiency measure in modern office buildings, the authors have designed and conducted a serial of field tests. Concentrations of aldehydes and TVOCs have been measured in two newly built and identical meeting rooms under different ventilation strategies. By overruling the existing demand control ventilation and increasing gradually but differently the air change rates in the rooms over a course of five weeks, the concentration of formaldehyde and TVOCs decreased for about $75 \%$ from the initial values of ca. $45 \mu \mathrm{g} / \mathrm{m}^{3}$ and ca. $400 \mu \mathrm{g} / \mathrm{m}^{3}$ respectively. Impact of door openings on instantaneous indoor air quality has been studied in parallel by combining $\mathrm{CO}_{2}$ measurements and numerical simulations. Good agreement was found between the simulated and measured $\mathrm{CO}_{2}$ concentrations and thereby the door opening model was verified.
\end{abstract}

\section{Introduction}

Characteristic odours from new objects and materials in newly built or renovated offices in Sweden are normally harmless but may cause temporary discomfort among occupants. By experience it is known that the odour intensity declines with time yet slower in less-used spaces. The latter can be explained by less ventilation since contemporary ventilation systems for office buildings in Sweden are operated on demand to save the energy for air conditioning and operation. While energy saving is very much in focus when designing systems and control schemes for ventilation, levels of non-occupantrelated air pollutants such as aldehydes and total volatile organic compounds (TVOCs) in indoor air that cause the odours in new facilities are not.

In compliance with the national regulations on healthy indoor environments, which specifies the functional performance of a building but not the means on how to achieve it, there is an established practice among building contractors of using low-emission building materials and building products to keep the non-occupant-related indoor air pollutants at desired levels [1]. Impact of emissions from furniture and other user-related objects in buildings is not considered in the regulations. After the building is put in use, the owner is responsible for maintaining the building so that its design and technical performances are preserved. Normally, there is no follow-up from the public body that the maintenance obligation is being met. Even if the building owner buys low-emission furniture, there is no information about the combined impact of the furniture and other (low-emissive) building materials on indoor air quality. Consequently, there are no data about non-occupant-related concentrations of indoor air pollutants that can be considered when designing and operating ventilation systems in buildings.

Properly designed ventilation is essential for achieving good indoor air quality (IAQ) regardless if it is combined with pollution source control, such as the use of low emission materials, or used in environments with uncontrollable pollution sources. Building materials can be large sources of indoor pollution [2], which is the reason why a lot of efforts have been put in designing lowemission materials and related standards [3]. $\mathrm{Ng}$ et al.[4] showed that the sole use of low emission materials is not a sufficient measure for securing IAQ if ventilation flow rates are low, or if not all chemicals that are emitted are accounted for in products' emission declarations. Järnström et.al [5] reported similar findings by showing that concentrations of VOCs can be high in new apartments in Finland even though only low-emission materials have been used.

Relations between ventilation rates and concentrations of indoor air pollutants are not always straightforward. While lower concentrations of formaldehyde have been measured in low-energy Swedish buildings that have significantly higher ventilation rates than the conventionally built houses, the opposite is found for TVOCs [6]. Concentration of $\mathrm{CO} 2$ in indoor air is a common control signal for the ventilation and removal of

\footnotetext{
* Corresponding author: angela.sasic@chalmers.se
} 
user-related air pollutants. However, the same signal is insufficient for the removal of non-occupant-related air pollution [7].

In new buildings, the concentration of indoor air pollutants decreases rapidly after the building is put in use and, based on [5], normal values are reached after 6 months. To catch and understand this process, the measurements on indoor air pollutants should be made as early as possible and preferably before the building is put in use [5]. Similar studies on early-stage VOCs emissions in Swedish buildings are rare although they may bring valuable insights into how IAQ differs within one building [8].

To bring more insights into the correlation between the ventilation rate and early-stage indoor emissions, the authors of this work have designed and conducted field tests where concentrations of aldehydes and TVOCs have been measured directly after a newly built office building has put in use. The field campaign has started in October 2019 and the data collected during selected five weeks from November to December 2019 are presented in this work. The field campaign included also an assessment of perceived indoor air quality by means of odour tests. To understand the impact of door openings on the concentration of indoor air pollution between the odour test, a building VOCs simulation model has been developed and verified by the measured data.

\section{Methodology}

The investigation combines measurements of aldehydes and TVOCs in the field and complementary numerical analysis. Since the early-stage emissions are of interest, the measurements have been conducted in a newly built office building named 'A Working Lab' at the Chalmers campus Johanneberg. The building was erected during 2019 and put in use in October the same year. It is a lowenergy building and ranked 'gold', which is the highest grade in the Swedish environmental certification systems for buildings [9]. The load-bearing system is made of cross-laminated timber (inner walls), steel frames and concrete (floors). There is a demand-controlled ventilation system in the building with temperature and presence sensors.

Besides the building's early age, the convenience of conducting measurements in two identical meeting rooms where the ventilation rates could be easily adjusted to the demands of the experiments where decisive details for choosing this building for the field tests. Other details of interests for the investigation are presented hereafter.

\subsection{Test rooms}

Samples of VOCs and aldehydes have been collected in two identical but differently ventilated rooms on floor 3 and 4 by means of diffusive samplers. Other parameters of indoor air such as temperature, relative humidity, $\mathrm{CO} 2$ and ventilation flow rates have been measured by an automatized system installed in the building.
Both rooms are placed inside the building, on top of each other and without connections to the outdoor environment. The size of the rooms is approximately $3 \times 4 \times 3.5 \mathrm{~m}$. The rooms have identical furniture, ventilation and auxiliary equipment (see Figure 1). Walls are cladded with gypsum boards and painted. There is a carpet on the entire floor. Other furniture and objects are: whiteboard on one wall, suspended ceiling of wooden acoustic panels, a table, 8 upholstered chairs, low shelf, coat hanger computer projector, central ceiling lamp, speakers, and spotlights for the whiteboard.
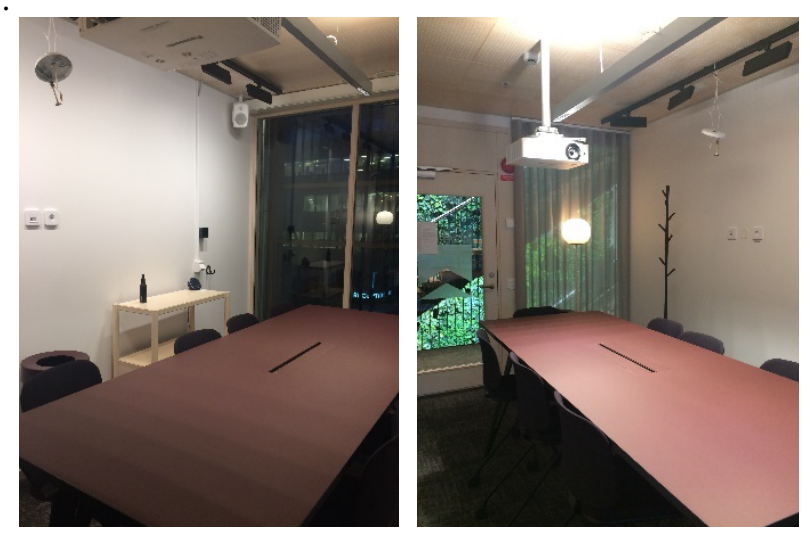

Fig. 1. Inside the test offices: office 3104 to the left and 4104 to the right. Aldehyde and TVOC samplers are fastened on the disks hanging from the spot-light rails below the ceilings.

\subsubsection{Ventilation schedules}

To find a correlation between ventilation flow rates and concentration of VOC in indoor air, the following ventilation campaign was implemented in the test rooms. The supply air to both test rooms was switched off for a week (week 44). Between weeks 45 to 52, the supply air in room 3104 was $10 \mathrm{l} / \mathrm{s}\left(\right.$ or $\left.1 \mathrm{~h}^{-1}\right)$. During the same period, the supply air to room 4104 was gradually increased and then varied as shown in Table 1. The general idea was to allow better ventilation in room 4104 than in 3104 .

Table 1. Prescribed supply air flow rates to the test rooms between weeks 44 - 52 (October 21 - December 29, 2019)

\begin{tabular}{|c|c|c|}
\hline \multirow{2}{*}{ Week } & \multicolumn{2}{|c|}{ Supply air flow rate (1/s) } \\
\cline { 2 - 3 } & Room 3104 & Room 4104 \\
& & \\
\hline 44 & 0 & 0 \\
45 & $10^{*}$ & 10 \\
$46-48$ & 10 & 20 \\
\hline
\end{tabular}

* $10 \mathrm{l} / \mathrm{s}$ corresponds to air change rate of app. $0.8 \mathrm{~h}^{-1}$

\subsubsection{VOC measurements}

The VOCs were passively collected on Tenax adsorbent medium (Perkin-Elmer tubes). The sampling and analysis followed the ISO 16017-2 standard [10]. Details of the 
analytical procedure for VOC are described elsewhere [6]. Shortly, the VOCs were thermally desorbed from adsorbent tubes into a gas chromatograph and detected by a mass spectrometer. TVOC were quantified in toluene equivalents. Aldehydes C1 - C10 (formaldehyde to decanal, including acetone) were sampled using DSDDNPH Aldehyde Diffusive sampling Device (Supelco, Bellefonte, PA). The sampling period and analytical technique (solvent extraction and high-performance liquid chromatography) followed the procedures described in the ISO 16000-4 standard [11]. The sampling period for both groups of organic compounds was 1 week. Details of the analytical procedures for aldehydes are described elsewhere [6].

\subsection{Numerical simulations}

As mentioned above, the field campaign included also an assessment of perceived indoor air quality by means of odour tests. The testing procedure involves a group of people - the odour panellists, who go into the test room at specified times, sniff the indoor air, leave the room and assess the air quality with help of a questionnaire.

It was anticipated that each door opening may change the quality of air in the room due to the air exchange with adjacent corridors. This would create different test conditions for the odour panellist and bias the results. To prevent this, a needed time difference between two consecutive odour tests has been investigated by means of numerical simulations. Time-varying concentration of an air pollutant has been modelled by the following equation:

$$
c(t)=c_{0} \cdot e^{-n \cdot t}+\left(c_{b g}+\frac{G}{V}\right) \cdot\left(1-e^{-n \cdot t}\right)
$$

where $c, c_{0}$ and $c_{b g}\left(\mathrm{~kg} / \mathrm{m}^{3}\right)$ are the concentrations of the pollutant in indoor air at time $t(\mathrm{~s})$, at the start of observation $(t=0)$, and in the supply air respectively, $n$ $(1 / \mathrm{s})$ is the ventilation air change rate, $V\left(\mathrm{~m}^{3}\right)$ is the volume of the room, and $G(\mathrm{~kg} / \mathrm{s})$ is a source of the indoor pollutant the room.

The equation (1) is a solution to the first order ordinary differential equation where one variable changes in time in a stepwise manner while others are constants. If one or more variables change stepwise in time, a more general solution can be produced by superposition of the partial solutions from equation (1). Examples of the superposition techniques can be found in i.e. [12]. The solution is valid for cases where there is no storage of air pollutants in materials and objects within the ventilated space. Door openings are short-time events and thus it is reasonable to exclude effects of secondary emissions. Examples of situations with secondary emissions can be seen in i.e. [13].

\subsubsection{Impact of door opening}

The mass balance equation (1) has been coded in Matlab to facilitate further numerical investigations. It is assumed that, when the testing panel enters and leaves the room, during a panel session, the door is opened for totally 15 seconds during which the supply ventilation rate increases with $40 \mathrm{l} / \mathrm{s}$. Consequently, the increased ventilation rate reduces the concentration of VOC's in the room. The remining input data to the model include the total volume of the room $36 \mathrm{~m}^{3}$ and the supply ventilation rate when the door is closed $35.4 \mathrm{l} / \mathrm{s}$.

The results from the simulation is shown in Fig. 2. According to the results the initial (and normalized) concentration in the room has recovered from the increased ventilation (when the door opened) after approximately one hour. To be sure that the indoor condition in the consecutive odour test is not affected by the first test, the tests were planned with at least two hours in between.

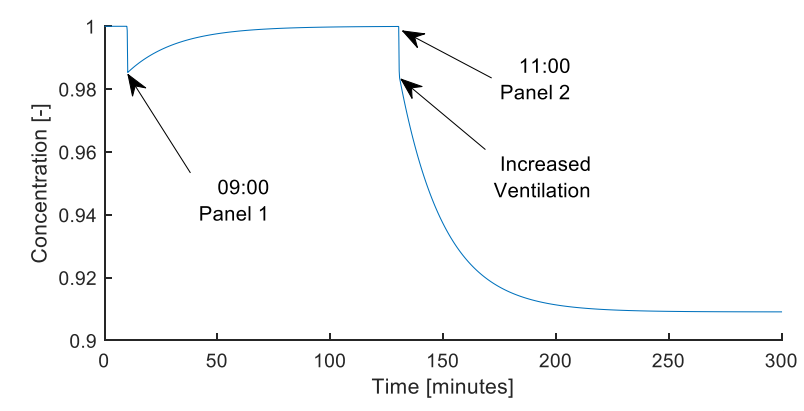

Fig. 2. Change of the normalized concentration of the air pollutant in time after door opening. Results of numerical simulations.

\section{Results}

\subsection{Measured air flow rates}

Fig. 3 and shows that the measured supply flow rates to the rooms were within $\pm 1 \mathrm{l} / \mathrm{s}$ limits in respect to the prescribed values. On average, the supply flow rates to room 3104 and room 4104 were $9.8 \mathrm{l} / \mathrm{s}$ and $13.7 \mathrm{l} / \mathrm{s}$ respectively. The notable differences between the measured and prescribed air flow rates from Table 1 were mostly intentional. During technical interventions, meetings, or similar gatherings, larger supply flow rates were allowed, up to $40 \mathrm{l} / \mathrm{s}$, to keep the rooms cool. Certain larger air flow rates could have been just accidental due to diverse adjustments of HVAC systems. Unexpectedly, records from the presence sensors in the rooms were insufficient, missing the data during several confirmed visits to the rooms, to make further conclusions in this regard. Instead, readings from $\mathrm{CO} 2$ are included in Figure 4 to show how often and to what extent the indoor environment has changed.

Finally, the measured indoor temperatures are shown in Figure 5. The room 4104 was cooler for about $1{ }^{\circ} \mathrm{C}$ than room 3104 during the measurements. This temperature difference can be, at least partly, explained by larger supply flow rates in room 4104 but also by the tolerances for the temperature control system. 

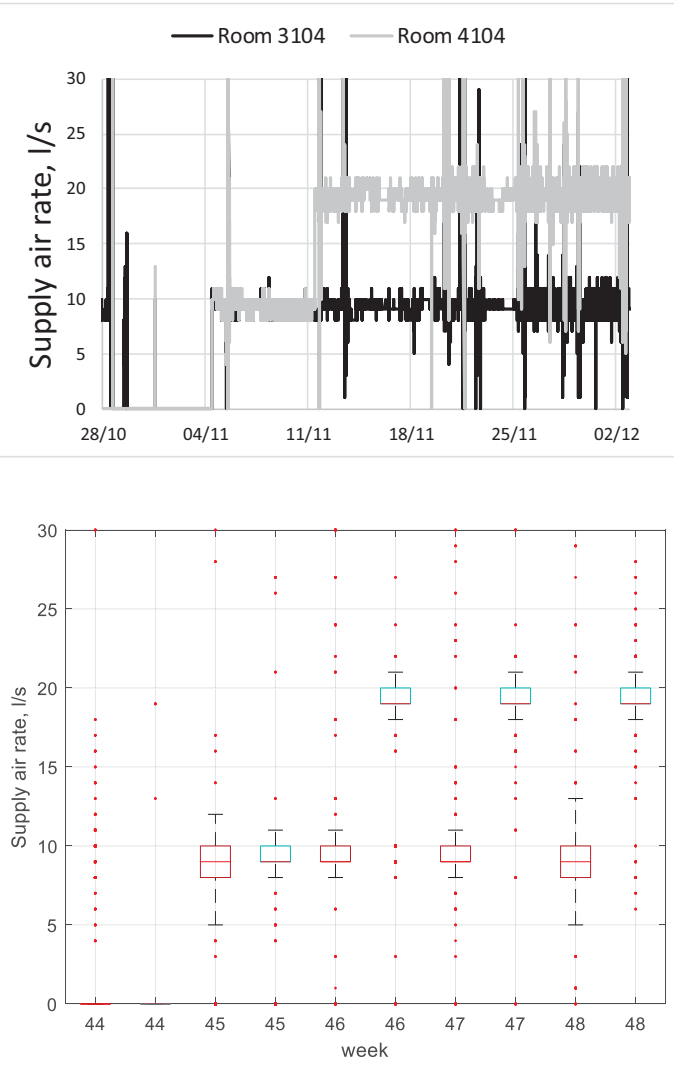

Fig. 3. Measured supply air change rates in the rooms. Top: time serials, sampling time about $3 \mathrm{~min}$. Bottom: weekly means and variances. Results for the offices 3104 and 4104 presented in an alternate manner, with the first box in a week corresponding to office 3104 . Week 44 is October 28 to November 4, etc.

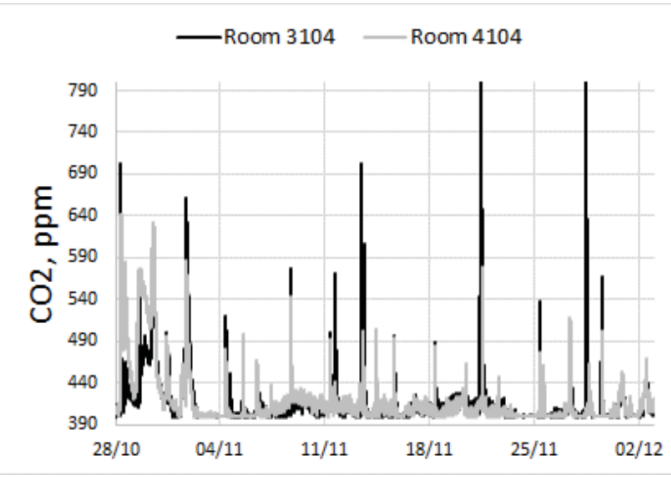

Fig. 4. Measured $\mathrm{CO} 2$ concentrations in the test rooms.

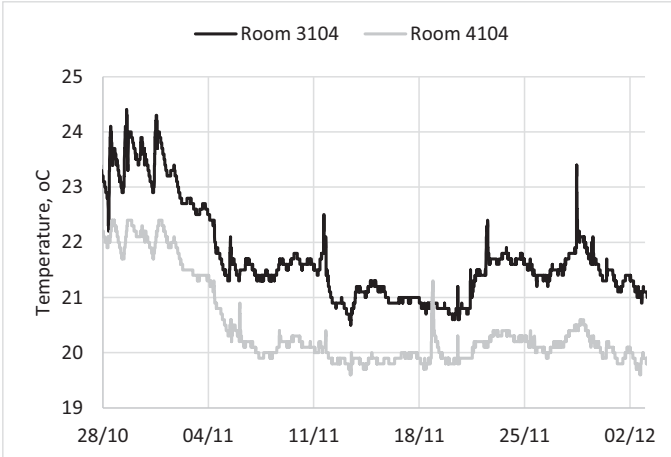

Fig. 5. Measured indoor air temperatures in the test rooms.

\subsection{Measured VOC}

As it is shown in Figure 6, the concentration of TVOCs decreased significantly after the ventilation was started in the rooms. Since the guiding values for Sweden are missing, both the initial and later measured concentrations of TVOCs can be compared with values in international references. For example, German Federal Environmental Agency [14] proposed the guideline values for TVOC in the range $200-300 \mu \mathrm{g} / \mathrm{m}^{3}$. Chronic exposure limit for formaldehyde proposed in French guidelines [15] is 10 $\mu \mathrm{g} / \mathrm{m}^{3}$. The TVOCs values were below the guideline value as soon as the active ventilation was implemented, i.e. from week 45 and on. The levels of formaldehyde also decreased sharply with the ventilation on-going as it can be seen in Figure 7. In room 4104, the levels did not reach a value below the chronic exposure level.

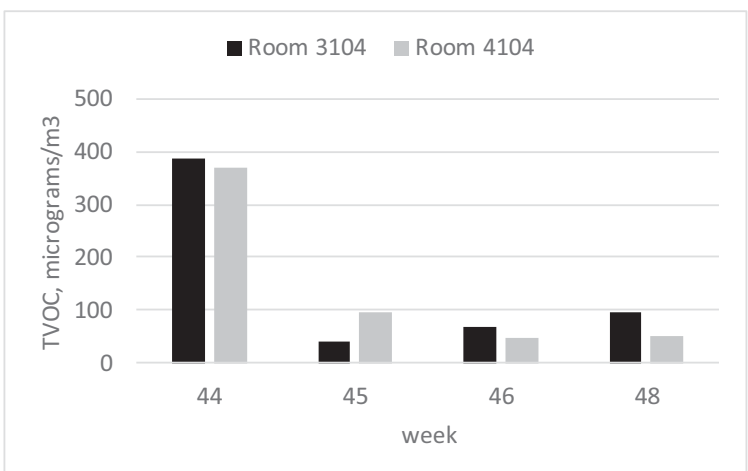

Fig. 6. Measured concentrations of TVOCs. The values show time averaged concentrations over approximately 5 (working) days.

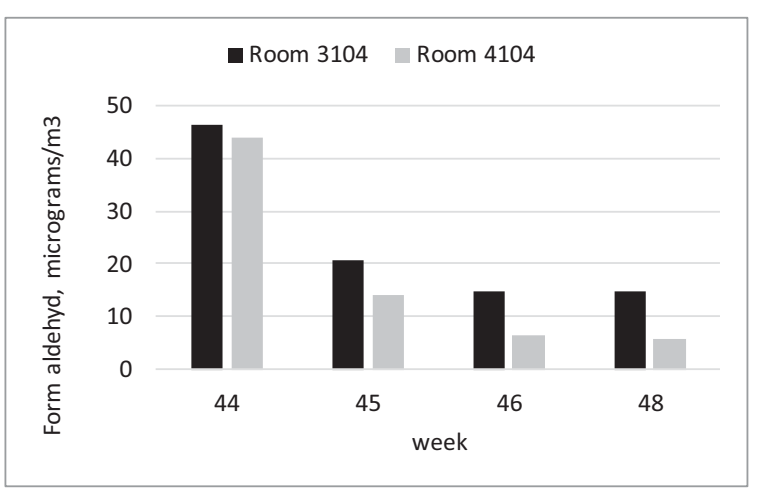

Fig. 7. Measured concentrations of formaldehyde. The values show time averaged concentrations over approximately 5 (working) days.

\subsection{Verification of the door opening study}

Because the readings from the passive aldehyde and TVOC samplers give time-averaged concentrations of these pollutants rather than their variations in time, to verify the mass balance equation 1 a comparison is made with measured $\mathrm{CO}_{2}$ concentrations in one of the test rooms. Ventilation rates used in the calculation are gathered from loggers in the ventilation system of the building. Since it is not known at what times people are present in the room, peaks in $\mathrm{CO}_{2}$ concentrations are used as indicators instead. The $\mathrm{CO}_{2}$ source in the model is 
therefore turned on to match the measured peaks in concentration. The source the term is based on measured values for one person doing lighter work such as typing [16].

Table 2. Input data for the simulation

\begin{tabular}{|c|c|c|}
\hline Variable & Quantity & Unit \\
\hline$c_{0}, c_{b g}$ & 400 & $\mathrm{ppm}$ \\
\hline$n$ & 0.69 & $1 / \mathrm{h}$ \\
\hline$V$ & 42 & $\mathrm{~m}^{3}$ \\
\hline$G$ & 24 & $\mathrm{~L} / \mathrm{h}$ \\
\hline
\end{tabular}

The results can be seen in Figure 8. Simulated results match well with the measurements. However, the peak values are generally higher in the simulation. One explanation for this is a possible delay in the measurement sensor, which means that measurements do not necessarily record the actual peak values at all times.

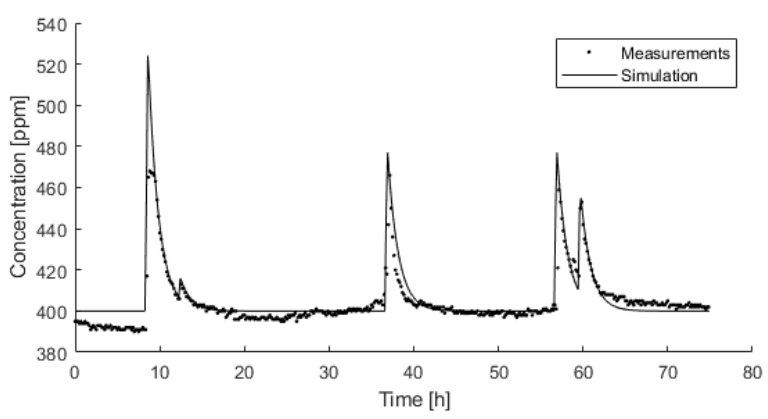

Fig. 8. Simulated concentration of $\mathrm{CO} 2$ compared to measured concentrations in one of the test rooms.

The fact that the equation (1) captures correctly the slope and decline of the concentration peaks, indicates that the model is adequate for estimating the time needed between test panels, section 2.2.1

\section{Conclusions}

The levels of TVOC and formaldehyde decreased when the room started to be ventilated. The decrease of TVOC was not consistently proportional to the increase of ventilation flow rates. In the less ventilated room 3104, the level of TVOC was firstly lower than in the better ventilated room 4104, and thereafter higher and gradually increasing along the measurement period. Reasons for this outcome cannot be identified with certainty before measurements from longer periods are available. One can conclude that levels of TVOC are similar regardless the ventilation flow rates. Formaldehyde shows more expected behaviour, it decreases approximately exponentially and more in the more ventilated room.

Impact of door openings on instantaneous indoor air quality has been studied by combining $\mathrm{CO}_{2}$ measurements and numerical simulations. Good agreement was found between the simulated and measured $\mathrm{CO}_{2}$ concentrations and, thereby, the door opening model was verified.

\section{References}

1. Kemikalieinspektionen, "Hälsoskadliga kemiska ämnen i byggprodukter - förslag till nationella regler, rapport 8/15."

2. P. Wolkoff, "How to measure and evaluate volatile organic compound emissions from building products. A perspective," Sci. Total Environ., vol. 227, no. 23, pp. 197-213, Mar. (1999).

3. H. Järnström, Reference values for building material emissions and indoor air quality in residential buildings. VTT Technical Research Centre of Finland, (2007).

4. L. Ng, D. Poppendieck, W. S. Dols, and S. J. Emmerich, "Evaluating indoor air quality and energy impacts of ventilation in a net-zero energy house using a coupled model," Sci. Technol. Built Environ., vol. 24, no. 2, pp. 124-134, (2018).

5. H. Järnström, K. Saarela, P. Kalliokoski, and A.-L. Pasanen, "Reference values for indoor air pollutant concentrations in new, residential buildings in Finland," Atmos. Environ., vol. 40, no. 37, pp. 71787191, Dec. (2006).

6. S. Langer, G. Bekö, E. Bloom, A. Widheden, and L. Ekberg, "Indoor air quality in passive and conventional new houses in Sweden," Build. Environ., vol. 93, no. P1, pp. 92-100, (2015).

7. C. Y. H. Chao and J. S. Hu, "Development of a dualmode demand control ventilation strategy for indoor air quality control and energy saving," Build. Environ., vol. 39, no. 4, pp. 385-397, (2004).

8. S. Langer and K. Hallgren, Innemiljö $i$ HSB Living Lab En studie av innemiljön under en fastighets första år. (2018).

9. SGBC, "Miljöbyggnad - Sweden Green Building Council - Sweden Green Building Council." [Online]. Available: https://www.sgbc.se. [Accessed: 23-Jan-2020].

10. ISO, ISO 16017-2:2003 - Indoor, ambient and workplace air - Sampling and analysis of volatile organic compounds by sorbent tube/thermal desorption/capillary gas chromatography - Part 2: Diffusive sampling. 2003.

11. ISO, ISO 16000-4:2004 - Indoor air - Part 4: Determination of formaldehyde - Diffusive sampling method. 2004.

12. C. E. Hagentoft, Introduction to Building Physics. Studentlitteratur, (2001).

13. H. Karlsson, A. S. Kalagasidis, and C.-E. Hagentoft, "Development of a modular toolbox in simulink for dynamic simulations of voc-concentration in indoor air," in IBPSA 2005.

14. GFEA, "German Committee on Indoor Guide Values I Umweltbundesamt," (2005). [Online]. Available: https://www.umweltbundesamt.de. [Accessed: 23Jan-2020].

15. CSTB, "Indoor Air Quality Guidelines. French Agency for Food, Environmental and Occupational Health \& Safety," (2007).

16. E. Abel and A. Elmroth, Buildings and Energy - $a$ systematic approach. Gothenburg: Formas, (2007) 